\title{
Quantitative proteomic analysis and comparison of two bone marrow stromal cell lines using SILAC method
}

Xiang $\mathrm{Li}^{1}$, Ting Wan ${ }^{1}$, Sijie Zhang ${ }^{2}$, Dongliang $\mathrm{Li}^{1}$, Xiaofeng $\mathrm{Han}^{1}$ *

${ }^{1}$ Wuxi Medical School, Jiangnan University, Wuxi, China.

${ }^{2}$ The Key Laboratory of Carbohydrate Chemistry \& Biotechnology, Ministry of Education; School of Biotechnology, Jiangnan University, Wuxi, China.

* Corresponding author. Mailing address: Wuxi Medical School, Jiangnan University, Wuxi, China. Fax: +86-0510-85918126. E-mail: xfenghan@126.com. 


\begin{abstract}
Two human bone marrow stromal cell lines, HS5 and HS27a, co-cultured with myeloid cells, have been frequently used in studies of crosstalk between cells in the bone marrow microenvironment and hematopoietic cells. Altered expression of proteins is typically associated with cell-cell signal transduction and regulation of cellular functions. Many studies have focused on key proteins that contribute to functional differences in cell co-culture models, but global quantitative proteome of HS5 and HS27a has not been performed. We applied the SILAC method using two stable isotopes each of arginine and lysine for labeling of proteins in the two cell lines. Labeled proteins were by 2D ultrahigh-resolution liquid chromatography LTQ Orbitrap mass spectrometry. Among 4213 unique identified and annotated proteins in the cell lines, 1462 proteins were detected in two independent experiments. Of these, 69 showed significant upregulation and 48 showed significant downregulation (>95\% confidence) in HS27a relative to HS5. Gene ontology (GO) term and pathway analysis indicated that the differentially regulated proteins were involved in cellular movement, cell-to-cell signaling and interaction, and hematological system development and function. A total of 55 items were identified in both genomic and proteomic databases. Quantitative RT-PCR and western blotting were performed on 7 proteins randomly selected from 28 differentially expressed proteins that were identified in both databases and were involved in the top networks/pathways. We observed that the decreased apoptosis in co-cultured KG1a cells when integrin $\alpha \mathrm{V}$ (ITGAV) was inhibited in HS27a cells, which suggested the functional role of ITGAV in co-culture system. The integrated genomic/ proteomic approach described here, and the identified proteins, will provide a useful basis for further elucidation of molecular mechanisms in the bone marrow microenvironment, and for ongoing studies of crosstalk among stromal cells and myeloma cells in co-culture systems.
\end{abstract}




\section{INTRODUCTION}

Bone marrow stromal cells, the major component of bone marrow, have many important functions besides acting as "silent partners" of hematopoietic cells. They secrete growth factors and insoluble matrix factors that promote clonal cell survival, and recruit endothelial, inflammatory, and mesenchymal stem cells [1]. According to the "Seed and Soil" theory, homing factors from stromal cells in the bone marrow microenvironment promote the growth of clonal cells, e.g., myelodysplastic syndromes (MDS) cells, and are involved in clonal diseases of hematopoietic stem/ precursor cells [2-5]. Increasing evidence indicates that bone marrow stromal cells are enriched in growth factors, cytokines, and proteases, and provide a favorable environment for docking of circulating cells such as prostate cancer cells $[6,7]$. Bone marrow stromal cell lines HS5 and HS27a represent two major types of cells related to early cancer development and are useful for deciphering crosstalk between stromal cells and clonal cells. HS27a supports "cobblestone area" formation by early hematopoietic progenitor cells, whereas HS5 secretes multiple cytokines that support proliferation of committed progenitor cells [8]. Apoptosis-resistant clonal MDS progenitor cells from patients with advanced MDS became sensitive to TNF $\alpha$-induced apoptosis through contact with HS5 or HS27a cells [9-11]. Co-administration of HS27a (but not HS5) cells with hematopoietic progenitor cells from MDS patients facilitated engraftment of clonal $\mathrm{CD} 34^{+}$cells of any karyotype [5], indicating that the two stromal cells have differing functions in support of primitive clonal MDS cells. A study of the mechanism of preferential bony metastasis of human prostate cancer (PCa) cells suggested that HS5 and HS27a cells activate trans differentiation apoptotic resistant PCa cells, promoting their adaptation to the bone microenvironment and eventual development of lethal disease [6]. These two stromal cell lines, available from the American Type Culture Collection (ATCC; Manassas, VA, USA), thus provide a very useful model for studies of tumor cell/ stromal cell interactions [12-14].

Over 17,000 genes in the HS5 and HS27a cell lines have been characterized and compared using DNA microarray techniques [8]. However, whole-proteome information is not available for either cell line, and integrated analysis using differential genomic and proteomic techniques has not been performed. Recent advances in mass spectrometry (MS) for protein identification and quantification provide several approaches for in-depth analysis of a large number of proteins [15-17]. The SILAC ("Stable Isotope Labeling by Amino acids in Cell culture") method has many advantages over other methods; e.g., it reduces sample-to-sample variability and is highly suitable for protein quantification [18]. In the present study, proteomic differences between HS5 and HS27a cells were analyzed using two stable isotopes each of arginine (Arg) and lysine (Lys) in two separate cultures: "light" (K0R0, L) and "heavy" (K8R10, H) (Fig. 1). The distinctive "L" and "H" forms of each peptide pair, having $\mathrm{m} / \mathrm{z}$ difference 8 or 10 as detected by MS, reflected relative amounts of the 
corresponding protein in each of the two isotopically encoded stromal cells. Labeled proteins with $>95 \%$ label incorporation were analyzed and quantified by 2D-HPLC-LTQ Orbitrap MS. We integrated information on differentially expressed proteins with genomic data available from open access, validated these data by RT-PCR and western blotting of the two cell lines, and evaluated functions of the differentially expressed proteins using an Ingenuity Systems software program. We observed upregulation (at both protein and mRNA levels) of proteins such as HCLS1, COL1A2, and ALCAM in HS27a, and proteins such as HSP90 and CSE1L in HS5. These findings increase our knowledge of these two stromal cell lines, and provide a useful basis for future functional studies.

\section{MATERIALS AND METHODS}

\section{Cell culture}

KG1a cells (derived from AML) and bone marrow stromal cell lines HS5 and HS27a were grown, propagated, and subjected to experiments between passages 8 and 24, as described previously [11]. For SILAC labeling, stroma cells were cultured in SILAC-labeled RPMI 1640 medium with 10\% dialyzed FBS and 1\% penicillin/ streptomycin containing "light" (K0R0), or "heavy" (K8R10) Lys and Arg, respectively [19]. L-proline (200 mg/L) was added to medium to prevent Arg-to-proline conversion [20, 21]. Labeled cells were cultured in SILAC medium for $\geq 6$ passages to eliminate the presence of native Lys and Arg.

Genomic analysis using open access data

Differential gene expression of HS5 and HS27a was analyzed by Beverly Torok-Storb's group (Fred Hutchinson Cancer Research Center; Seattle, WA, USA) as described previously, and data were made available by open access at ncbi.nlm.nih.gov/geo/geo2r/?acc=GSE463 [8]. In brief, a table populated with sample characteristics is shown on the web interface. We designate up to 8 sample groups for comparison, choose parameters, and click the "GEOquery" button. The results table presents various categories of statistics (P-values, t-statistics, fold change values) and gene annotations (gene symbols, gene names) [22].

\section{Cell lysis and protein extraction}

Total proteins were extracted from cells using T-PER reagent (Thermo Scientific; San Jose, CA, USA). In brief, $1 \times 10^{7}$ cells were detached with trypsin, washed with ice-cold $1 \times \mathrm{PBS}(0.01 \mathrm{M}$ phosphate buffer containing $0.15 \mathrm{M} \mathrm{NaCl}, \mathrm{pH} 7.4)$, lysed with $0.5 \mathrm{~mL}$ T-PER reagent containing 1 $\mathrm{mM}$ PMSF and $0.1 \%$ aprotinin, incubated for $30 \mathrm{~min}$ on ice, homogenized, and centrifuged at 12,000 
rpm for 15 min. Protein concentration was measured by BCA assay (Beyotime; Haimen, China).

\section{$\underline{\text { SDS-PAGE and in-gel digestion }}$}

Proteins were separated by $10 \%$ SDS-PAGE and visualized by Coomassie staining. Gel slices were washed with $25 \mathrm{mM}$ ammonium bicarbonate/ 50\% acetonitrile (ACN), dried, incubated with 20 $\mu \mathrm{L}$ of $10 \mathrm{mM}$ dithiothreitol (DTT) at $56^{\circ} \mathrm{C}$ for $1 \mathrm{hr}$, transferred to equal volumes of $20 \mathrm{mM}$ iodoacetamide (IAM) at room temperature in the dark for $45 \mathrm{~min}$, washed, trypsinized using $20 \mu \mathrm{L}$ of $0.05 \mu \mathrm{g} / \mu \mathrm{L}$ trypsin (Promega; Madison, WI, USA) at $4{ }^{\circ} \mathrm{C}$ for $30 \mathrm{~min}$, subjected to removal of excess trypsin solution, added with $20 \mu \mathrm{L}$ of $25 \mathrm{mM} \mathrm{NH}_{4} \mathrm{HCO}_{3}$, and incubated at $37^{\circ} \mathrm{C}$ for $10 \mathrm{hr}$. Extracted products were dried using a SpeedVac concentrator (CentriVap Cold Trap, Labconco; Kansas, MO, USA). Dried samples were dissolved in $2 \mu \mathrm{L} 0.5 \%$ trifluoroacetic acid and subjected to MALDI-TOF/TOF-MS analysis (UltrafleXtreme, Bruker Daltonics; Bremen, Germany) for evaluation of amino acid substitutions.

\section{$\underline{\text { In-solution digestion }}$}

Proteins from stable isotope labeled cells were mixed at 1:1, reduced and alkylated by incubation with equal amounts of 10\% DTT and 10\% IAM, digested by lysyl endopeptidase (Wako; Osaka, Japan), and then digested by trypsin at $37^{\circ} \mathrm{C}$ for 4 or $12 \mathrm{hr}$ [23]. Total peptides were concentrated and desalted using a $10 \mathrm{kDa}$ size-exclusion spin ultrafiltration unit, eluted with varying concentrations of ACN, and dried using the SpeedVac concentrator.

\section{$\underline{\text { LC-MS/MS analysis }}$}

2D-LC-MS was performed using LTQ Orbitrap MS (Thermo Fisher; Waltham, MA, USA) as described previously [24]. In brief, digested peptides $(100 \mu \mathrm{g})$ were injected onto a biphasic capillary column (internal diameter $200 \mu \mathrm{m}$ ) packed with $\mathrm{C}_{18}$ resin (ReproSil-Pur, $5 \mu \mathrm{m}$, Dr. Maisch GmbH; Ammerbuch, Germany) and strong cation exchange resin (Luna, $5 \mu \mathrm{m}$, SCX 100A, Phenomenex; Torrance, California,USA). Peptide effluents of the biphasic column at each step were transferred to a 15-cm $\mathrm{C}_{18}$ analytical column (i.d. $75 \mu \mathrm{m}$; ReproSil-Pur, $3 \mu \mathrm{m}$ ) at flow rate $500 \mathrm{~nL} / \mathrm{min}$. Nano electrospray ionization (ESI) was performed with spray voltage $2.0 \mathrm{kV}$ and heated capillary at $200{ }^{\circ} \mathrm{C}$. One full MS scan (300-1800) using the Orbitrap was followed by five MS/MS scans of the five most intense ions selected from the MS spectrum in LTQ. Charge state screening was enabled for $+2,+3$, +4 , and above. 
Raw MS data were analyzed using the MaxQuant software program (V. 1.2.2.5) [25, 26]. A false discovery rate (FDR) of 0.01 for proteins and peptides and a minimum peptide length of 6 amino acids were required. MS/MS spectra were searched by Andromeda [27] against the International Protein Index (IPI) human database (V. 3.85). SILAC states of peptides were determined by the MaxQuant program from mass differences between SILAC peptide pairs, and this information was used for searches with fixed Arg10 or Lys8 modifications, as appropriate. Quantification in MaxQuant was performed as described previously [25].

Differential regulation within each experimental H/L (ratio of "heavy" to "light") of identified proteins was normalized using $\log _{2}$ (ratio) $= \pm 1$ as threshold and z-score analysis, as described previously $[28,29]$. In brief, $\mathrm{H} / \mathrm{L}$ ratios were converted into $\log _{2}$ space to determine geometric means, and average ratios and standard deviations were determined for each data set. The $\log _{2} \mathrm{H} / \mathrm{L}$ ratio for each protein was converted to a z-score using the formula shown below, in which $\mathrm{b}$ represents a single protein in a data set population $(\mathrm{a} \ldots . . \mathrm{n})$. The $\mathrm{z}$-score indicates the number of standard deviation units $(\sigma)$ the protein's $\log _{2} \mathrm{H} / \mathrm{L}$ ratio is away from the population mean. Thus, a z-score $\geq 1.960 \sigma$ indicates that the protein's differential expression lies outside the $95 \%$ confidence interval, $\geq 2.576 \sigma$ indicates that differential expression is outside the $99 \%$ confidence interval, and $\geq 3.291 \sigma$ indicates $99.9 \%$ confidence. A z-score $\geq 1.960 \sigma$ was considered significant. Extracted data from the two experiments were subjected to further functional analysis.

$$
\mathrm{z}-\operatorname{scores}(\sigma) \text { of }[\mathrm{b}]=\frac{\log _{2} \frac{X(M \text { or } H)}{L}[b]-\text { Average of }\left(\log _{2} \text { of each number, } a \ldots n\right)}{\text { Standard deviation of }\left(\log _{2} \text { of each number, } a \ldots n\right)}
$$

\section{Functional annotation and Ingenuity Pathway Analysis}

Identified proteins were analyzed using the SWISS-PROT database for classification of biological process, cellular component, and molecular function [30]. Significantly overrepresented gene ontology (GO) terms were identified using the Database for Annotation, Visualization and Integrated Discovery (DAVID) gene bioinformatics resources [31, 32]. Proteins determined to be differentially regulated by statistical analysis were arranged in an Excel spreadsheet, their IPI numbers were uploaded to the Ingenuity System application (www.ingenuity.com), and each number was mapped to its corresponding gene object in the Ingenuity Pathways Knowledge Base. Networks of the proteins were generated algorithmically based on their connectivity. Fisher's exact test was used to calculate p-values reflecting the probability that assignment of a particular biological function and/or disease to a network was due solely to chance.

\section{$\underline{\text { Western blot analysis }}$}


Total cell proteins were prepared and quantified by bicinchoninic acid assay (Pierce Biotechnology; Chicago, IL, USA), and equal amounts of protein $(20 \mu \mathrm{g})$ from each lysate were diluted in Laemmli SDS sample buffer and resolved by electrophoresis on $4 \%$ to $12 \%$ Bis-Tris precast NuPAGE gels (Invitrogen; Camarillo, CA, USA) in running buffer (50 mM 2-(N-morpholino) ethane sulfonic acid, $50 \mathrm{mM}$ Tris [tris(hydroxymethyl)aminomethane]) base, $0.1 \%$ SDS, and $1 \mathrm{mM}$ EDTA) as per the manufacturer's instructions. Proteins were transferred to PVDF membranes for immunoblotting. Membranes were blocked in 5\% nonfat dry milk diluted in Tris-buffered saline containing $0.1 \%$ Tween-20 (TBS-T) for $1 \mathrm{hr}$ at room temperature, and incubated overnight at $4{ }^{\circ} \mathrm{C}$ in 5\% nonfat dry milk /TBS-T containing rabbit anti-HCLS1 antibody (1:1000; Abcam; Cambridge, MA, USA), rabbit anti-COL1A2 antibody (1:500; ABclonal; Boston, MA, USA), rabbit anti-ALCAM antibody (1:5000; Abcam), rabbit anti-ITGAV antibody (1:1000; Cell Signaling Technology; Danvers, MA, USA), rabbit anti-MAP4 antibody (1:500; ABclonal), rabbit anti-HSP90 antibody (1:5000; Abcam), rabbit anti-CSE1L antibody (1:1000, Abcam), or rabbit anti-tubulin antibody (1:1000; Cell Signaling). Secondary goat anti-rabbit antibodies (1:2000; Santa Cruz Biotechnology; Santa Cruz, CA, USA) conjugated to horseradish peroxidase were used for enhanced chemiluminescence (Pierce Biotechnology), and membranes were exposed to film.

\section{Quantitative real-time PCR}

Total RNA from $1 \times 10^{5}$ cells was isolated using an RNApure Tissue Kit (CWBiotech; Beijing, China). First-strand cDNA was synthesized from total RNA using ReverTra Ace- $\alpha-{ }^{\circledR}$ (Toyobo; Osaka, Japan). Primers were designed using the DNAMAN program (V. 6.0.3; Lynnon Biosoft, Canada). Quantitative real-time PCR was performed by LightCycler-based SYBR Green I dye detection with UltraSYBR Mixture (CWBiotech). Gene expression was quantified by the $2^{-\Delta \Delta C \mathrm{~T}}$ method [11].

\section{Assessment of apoptosis}

KG1a cells were cocultured with unmodified or modified HS27a cells in the presence of TNF $\alpha$ at $25 \mathrm{ng} / \mathrm{mL}$ for $24 \mathrm{hrs}$. Apoptosis was determined in KG1a cells, which were removed with the stroma after trypsin treatment. Cells were then labeled with FITC-conjugated anti-CD45 antibody to distinguish $\mathrm{CD}^{+} 5^{+}$cells from $\mathrm{CD} 45^{-}$cells (stroma cells) and analyzed by FACS for apoptosis using annexin $\mathrm{V}$-phycoerythrin and propidium iodide.

\section{RESULTS}


The SILAC method was used to analyze functional differences of HS5 and HS27a cells at the proteome level. Because incomplete labeling results in errors in quantification, and quantitation of low-abundance proteins may be masked by contaminated "light" peptides, cells were cultured in SILAC medium for a period of time sufficient to allow full incorporation of the stable isotope. To ensure complete labeling of proteins, particularly for labeling efficiency $>95 \%$, we performed a pilot experiment to determine incorporation efficiency of labeled Lys and Arg, "light" (HS5) and "heavy" (HS27a) proteins. MALDI-TOF/TOF-MS results for peptide GVVDSEDLPLNISR of heat shock protein 90- $\beta$ ( HSP90, P08238) indicated that complete incorporation of isotopically labeled Arg and Lys was achieved in HS5 and HS27a, and no Arg-to-Pro conversion occurred (Fig. 2A,B). LC-ESI-MS/MS analysis of the triply-charged peptide HLEINPDHPIVETLR of HSP90 and YGGPYHIGGSPFK of filamin-A (P21333) showed that these doublets of actual peak clusters were from HS5 and HS27a cells, respectively (Fig. 2C,D).

\section{$\underline{\text { SILAC cell model for quantification of proteome in HS5 and HS27a }}$}

Peptides from HS5 and HS27a were analyzed by ultrahigh-resolution liquid chromatography-tandem MS (nLC-ESI-MS/MS) on a hybrid linear ion trap LTQ Orbitrap instrument. A total of 4218 unique proteins were identified in two independent experiments (Fig. 3A). Of these, 1462 proteins ( $34.7 \%$ of the total) that were identified in both experiments and satisfied the criteria for protein quantitation were subjected to further bioinformatic analysis. Distribution histograms of H/L $\log$ ratios fit a Gaussian distribution (Fig. 3B,C). Most of the identified proteins were within the \pm 1 range of $\log$ ratios. Using \pm 1 as threshold $\log _{2}$ ratio, we found that expression of 131 proteins was upregulated and that of 96 proteins was downregulated in HS27a in comparison with HS5 (Fig. 3D). Population distribution-based z-scores allowed direct comparison of proteins from different experiments. Differing confidence level cutoffs were applied to the data in z-score analysis to determine which proteins showed significant differential regulation. The cutoffs applied were 95\%, $99 \%$, and $99.9 \%$, corresponding respectively to z-scores of $\pm 1.960, \pm 2.576$, and \pm 3.291 . Using $95 \%$ as cutoff, significant differential regulation of 117 proteins (69 upregulated, 48 downregulated) was observed in HS27a as comparead with HS5. Using 99\% as cutoff, differential regulation of 60 proteins (34 upregulated, 26 downregulated) was observed in HS27a. Using 99.9\% as cutoff, only 28 proteins (16 upregulated, 12 downregulated) showed differential regulation in HS27a. These results are summarized in Table 1. Downregulated and upregulated proteins determined in the two experiments using 95\% as cutoff are listed respectively in Tables 2 and 3. All proteins differentially regulated with $>95 \%$ confidence had $a>2$-fold alteration of SILAC ratio $\left(\log _{2}\right.$ ratio $>1$ or $\left.<-1\right)$. 
Functional classification and pathway analysis of identified proteins

Functional interpretation is a crucial step in data analysis when extensive functional annotation of the data sets is not available. Taking into account their nonexclusive localization in GO, the identified proteins were linked to at least one annotation term each within the GO molecular function, biological process, and molecular component categories. The most common molecular functions were binding (49.0\%), and catalytic activity (23.1\%) (Fig. 4A). The major biological process categories were cellular (14.2\%) and single-organism (13.2\%) (Fig. 4B). The major cellular component categories were cell part (17.9\%) and organelle (16.8\%) (Fig. 4C).

Proteins with $\log _{2}$ ratio \pm 1 were further analyzed, and metabolic and canonical pathways and interconnecting proteins were generated by Ingenuity Pathway Analysis. Proteins identified in the top network were involved in cellular movement, cell-to-cell signaling and interaction, hematological system development and function, scored as 44 (28 proteins; Fig. 5A). Proteins identified in other networks were involved in infectious diseases, post-translational modification, protein folding (23 proteins; Fig. 5B), and connective tissue disorders, dermatological diseases and conditions, and developmental disorders (23 proteins; Fig. 5C).

\section{Integrated analysis of proteomic and genomic data in HS5 and HS27a}

The next step was to perform integrated analysis of proteomic and genomic data from HS5 and HS27a cells. A total of 55 items were identified in both databases. Among these, 32 genes/proteins were upregulated in HS27a relative to HS5, including insulin-like growth factor-binding protein 7 (IGFBP7; SILAC $\log _{2}$ ratio 3.591; Gene array $\log _{2}$ ratio 4.536), collagen alpha-2(V) chain (COL5A2; SILAC $\log _{2}$ ratio 3.328; Gene array $\log _{2}$ ratio 2.494), hematopoietic lineage cell-specific protein (HCLS1; SILAC $\log _{2}$ ratio 2.979; Gene array $\log _{2}$ ratio 1.685), and cysteine and glycine-rich protein 2 (CSRP2; SILAC $\log _{2}$ ratio 2.644; Gene array $\log _{2}$ ratio 1.653). The other 23 genes/proteins were downregulated in HS27a relative to HS5 cell; these included ankyrin repeat and SOCS box protein 1 (ASB1; SILAC $\log _{2}$ ratio -3.065; Gene array $\log _{2}$ ratio -2.236), band 4.1-like protein 3 (EPB41L3, SILAC $\log _{2}$ ratio -2.930; Gene array $\log _{2}$ ratio -6.749), transmembrane glycoprotein NMB (GPNMB, SILAC $\log _{2}$ ratio -2.576; Gene array $\log _{2}$ ratio -5.310), and plasminogen activator inhibitor 2 (SERPINB2, SILAC $\log _{2}$ ratio -2.050; Gene array $\log _{2}$ ratio -5.542). We further compared the 69 upregulated and 48 downregulated proteins with the gene expression profiling that showed 10-fold higher and 10-fold lower expression, in HS27a cells than in HS5 cells [8]. We found Insulin-like growth factor binding protein 7 (IGFBP7) was significantly upregulated in both proteomic and gene expression database. In addition, band 4 like protein 3 (EPB41L3) and transmembrane glycoprotein NMB (GPNMB) were downregulated in both proteomic and gene expression database. 
Validation of MS results by real-time PCR (RT-PCR) and western blotting

To confirm the accuracy of protein identifications made by nLC-ESI-MS/MS, we randomly selected 7 out of the 28 differentially expressed proteins that were identified from both genomic and proteomic data and involved in the top networks shown in Fig. 5A, for validation of mRNA and protein levels. Annotations of the genes encoding these proteins are shown in Fig. 6A. We validated the genomic and proteomic data by RT-PCR and western blotting (Fig. 6B,C). Relative to HS5, mRNA and protein levels of HCLS1, COL1A2, and ALCAM were higher in HS27a, whereas mRNA and protein levels of MAP4, HSP90, and CSE1L were lower in HS27a. These findings are consistent with proteomic and genomic data. However, in the case of ITGAV, expression from the genomic database was slightly lower in HS27a relative to HS5, whereas protein level from the proteomic database was higher (Fig. 6A). Validation by RT-PCR and western blotting showed that ITGAV levels were higher in HS27a at both mRNA and protein levels. We then inhibited the expression of integrin $\alpha \mathrm{V}$ (ITGAV) in HS27a cells by specific siRNAs, and observed the decreased apoptosis in KG1a cells after co-cultured with modified HS27a cells under TNF $\alpha$ induction (Fig. 6 D and 6 E).

\section{DISCUSSION}

Human marrow stromal cell lines HS27a and HS5 have been used in studies of MDS as well as various types of cancer. We previously characterized glycan expression levels in these two cell lines using an integrated strategy combining gene microarray, proteomic, and lectin microarray analyses [33]. However, integrated analysis using differential genomic and proteomic techniques has not yet been performed. In the present study, we combined SILAC proteomic techniques with genomic data to elucidate additional signaling pathways related to cell-cell interactions in these two cell lines. A total of 1462 proteins out of 4218 unique proteins were identified in both experiments and met the criteria established for protein quantitation. Using +1 as the threshold $\log _{2}$ ratio, we found that expression of 131 proteins was upregulated and that of 96 proteins was downregulated in HS27a relative to HS5. Using 95\% as cutoff, significant differential regulation was observed for 117 proteins: 69 upregulated and 48 downregulated in HS27a relative to HS5.

We then integrated our proteomic data with available genomic data for the two cell lines. A total of 55 items were identified in both genomic and proteomic databases. The differential presentation between gene and protein expression may be resulted by, 1) most of protein are posttranslational modified; 2) the trace expression of certain protein were undetectable by current proteomic technique; and 3) the differential technique and analysis strategy used in genome and 
proteome research. GO analysis revealed that most of the common molecular functions were involved in binding and catalytic activity. The major biological process categories were cellular and single-organism, and the major cellular component categories were cell part and organelle. We were interested to find additional molecules that may facilitate cell-cell signaling pathways. Ingenuity Pathway Analysis indicated that identified proteins in the top network were involved in cellular movement, cell-to-cell signaling and interaction, and hematological system development and function; this was consistent with our criteria for supportive and commutative functions of stromal cells. We selected proteins HCLS1, COL1A2, ALCAM, MAP4, HSP90, and CSE1L, which were in the top network, for validation by RT-PCR and western blotting. HCLS1, a well-known signaling protein, is regulated by phosphorylation and interacts with various partners (including Grb2, Syk phosphatidyl-inositol-3 kinase, Lck, Lyn, c-Fgr, Arp2/3, and F-actin) for regulation of immunological synapses, STAT protein activity, and clonal selection of lymphocytes [34]. COL1A2 (collagen alpha-2(I) chain) is present in most connective tissues [35]. ALCAM, also known as CD166 antigen, is a $100-105 \mathrm{kDa}$ type I transmembrane glycoprotein belonging to the immunoglobulin superfamily. ALCAM is expressed on activated T cells, activated monocytes, epithelial cells, fibroblasts, neurons, and melanoma cells. It is an important mediator of adhesion interactions and has been used as a cancer stem cell marker [36, 37]; these findings may be relevant to its function in co-cultured stromal cells. MAP4 (microtubule-associated protein 4), a major non-neuronal MAP, promotes microtubule assembly and counteracts destabilization of interphase microtubule catastrophe promotion. MAP4 interacts with cyclin $\mathrm{B}$, which targets cell division cycle 2 (CDC2) kinase to microtubules [38, 39]. Phosphorylation of MAP4 affects microtubule properties and cell cycle progression [39]. HSP90 (heat shock protein 90) is a chaperone protein that facilitates proper folding of other proteins, stabilizes other proteins against heat stress, and contributes to protein degradation. It is among the most highly expressed cellular proteins across all mammalian species, and stabilizes a number of proteins involved in tumor growth [40]. CSE1L, also known as Exportin-2, mediates re-export of importin-alpha from the nucleus to the cytoplasm after import substrates (cargos) have been released into the nucleoplasm [41]. We observed higher expression of ITGAV (integrin alpha-V) in HS27a relative to HS5 at both mRNA and protein levels, although genomic data indicated lower expression in HS27a. ITGAV is able to combine with multiple integrin beta chains to form different integrins, each of which can interact with extracellular matrix ligands. Besides its role in adhesion, ITGAV facilitates signal transduction [42]; We then observed the decreased apoptosis in co-cultured KG1a cells when inhibited ITGAV in HS27a cells, which suggested the functional role of ITGAV in co-culture system. Our further work will focus on the functional role of ITGAV in primary bone marrow stroma cells as well as the microenvironmental niche. 
Stromal cells function as important sensors of cell microenvironmental conditions, and help regulate a variety of signaling pathways in response to structural alterations of extracellular matrix or to cell interactions. We used quantitative proteomic analysis of SILAC-labeled proteins integrated with a free-access genomic database for global expression profiling of human bone marrow stromal cell lines HS5 and HS27a, which are frequently used for investigations of the bone marrow microenvironmental niche. Our findings provide a useful basis for our ongoing studies of crosstalk among stromal cells and hematopoietic cells in a co-culture system.

\section{Acknowledgments}

This study was supported by grants from the National Science Foundation of China (Nos. 81470294 and 31400691), Natural Science Foundation of Jiangsu Province (No. BK20140169), and Fundamental Research Funds for the Central Universities (No. JUSRP51619B). The authors are grateful to Dr. S. Anderson for English editing of the manuscript.

\section{Author Contributions}

X.L. and X.H. designed the research. X.L., T.W., S.Z., and D.L. performed the research and analyzed the data. X.L. wrote the paper. All authors read and approved the final manuscript. 


\section{REFERENCES}

1. Cogle CR, Saki N, Khodadi E, Li J, Shahjahani M, Azizidoost S. Bone marrow niche in the myelodysplastic syndromes. Leukemia Research. 2015;39(10):1020-7.

2. Raaijmakers MH, Scadden DT. Evolving concepts on the microenvironmental niche for hematopoietic stem cells (Review). Current Opinion in Hematology. 2008;15(4):301-6.

3. Raaijmakers MHGP, Mukherjee S, Guo S, Zhang S, Kobayashi T, Schoonmaker JA, et al. Bone progenitor dysfunction induces myelodysplasia and secondary leukaemia. Nature. 2012;464(7290):852-7.

4. Jing D, Wobus M, Poitz DM, Bornhauser M, Ehninger G, Ordemann R. Oxygen tension plays a critical role in the hematopoietic microenvironment in vitro. Haematologica. 2012;97(3):331-9.

5. Li X, Marcondes AM, Ragoczy T, Telling A, Deeg HJ. Effect of intravenous coadministration of human stroma cell lines on engraftment of long-term repopulating clonal myelodysplastic syndrome cells in immunodeficient mice. Blood Cancer Journal. 2013;3:e113.

6. Zhang C, Soori M, Miles FL, Sikes RA, Carson DD, Chung LW, et al. Paracrine factors produced by bone marrow stromal cells induce apoptosis and neuroendocrine differentiation in prostate cancer cells. The Prostate. 2011;71(2):157-67.

7. Windus LC, Glover TT, Avery VM. Bone-stromal cells up-regulate tumourigenic markers in a tumour-stromal 3D model of prostate cancer. Molecular Cancer. 2013;12(1):112.

8. Graf L, Iwata M, Torok-Storb B. Gene expression profiling of the functionally distinct human bone marrow stromal cell lines HS-5 and HS-27a. Blood. 2002;100(4):1509-11.

9. Marcondes AM, Li X, Tabellini L, Bartenstein M, Kabacka J, Sale GE, et al. Inhibition of IL-32 activation by + -antitrypsin suppresses alloreactivity and increases survival in allogeneic murine marrow transplantation model. Blood. 2011;118(18):5031-9.

10. Marcondes AM, Li X, Gooley TA, Milless B, Deeg HJ. Identification of DJ-1/Park-7 as a determinant of stroma-dependent and TNF $¥$-induced apoptosis in MDS by using mass spectrometry and phosphopeptide analysis. Blood. 2010;115(10):1993-2002.

11. Li X, Marcondes AM, Gooley TA, Deeg HJ. The helix-loop-helix transcription factor TWIST is dysregulated in myelodysplastic syndromes. Blood. 2010;116(13):2304-14.

12. Menon NV, Chuah YJ, Cao B, Lim M, Kang Y. A microfluidic co-culture system to monitor tumor-stromal interactions on a chip. Biomicrofluidics. 2014;8(6):064118.

13. Hu S, Gou X, Han H, Leung AY, Sun D. Manipulating cell adhesions with optical tweezers for study of cell-to-cell interactions. Journal of Biomedical Nanotechnology. 2013;9(2):281-5.

14. Iwata M, Torok-Storb B, Wayner EA, Carter WG. CDCP1 identifies a CD146 negative subset of marrow fibroblasts involved with cytokine production. PloS One. 2014;9(10):e109304.

15. Rong Y, Jin D, Hou C, Hu J, Wu W, Ni X, et al. Proteomics analysis of serum protein profiling in pancreatic 
cancer patients by DIGE: up-regulation of mannose-binding lectin 2 and myosin light chain kinase 2 . BMC Gastroenterology. 2010;10(1):68.

16. Chen J-S, Chen K-T, Fan C-W, Han C-L, Chen Y-J, Yu J-S, et al. Comparison of membrane fraction proteomic profiles of normal and cancerous human colorectal tissues with gel-assisted digestion and iTRAQ labeling mass spectrometry. FEBS Journal. 2010;277(14):3028-38.

17. Caceres NE, Aerts M, Marquez B, Mingeot-Leclercq MP, Tulkens PM, Devreese B, et al. Analysis of the membrane proteome of ciprofloxacin-resistant macrophages by stable isotope labeling with amino acids in cell culture (SILAC). PloS One. 2013;8(3):e58285.

18. Ong S-E, Blagoev B, Kratchmarova I, Kristensen DB, Steen H, Pandey A, et al. Stable isotope labeling by amino acids in cell culture, SILAC, as a simple and accurate approach to expression proteomics. Molecular \& Cellular Proteomics. 2002;1:11.

19. Yang G, Xu Z, Lu W, Li X, Sun C, Guo J, et al. Quantitative analysis of differential proteome expression in bladder cancer vs. normal bladder cells using SILAC method. PloS One. 2015;10(7):e0134727.

20. Parmar K, Mauch P, Vergilio JA, Sackstein R, Down JD. Distribution of hematopoietic stem cells in the bone marrow according to regional hypoxia. Proceedings of the National Academy of Sciences of the USA. 2007;104(13):5431-6.

21. Annabi B, Lee YT, Turcotte S, Naud E, Desrosiers RR, Champagne M, et al. Hypoxia promotes murine bone-marrow-derived stromal cell migration and tube formation. Stem Cells. 2003;21(3):337-47.

22. Barrett T, Wilhite SE, Ledoux P, Evangelista C, Kim IF, Tomashevsky M, et al. NCBI GEO: archive for functional genomics data sets--update. Nucleic Acids Research. 2013;41(Database issue):D991-5.

23. Harrison JS, Rameshwar P, Chang V, Bandari P. Oxygen saturation in the bone marrow of healthy volunteers. Blood. 2002;99(1):394.

24. Azab AK, Hu J, Quang P, Azab F, Pitsillides C, Awwad R, et al. Hypoxia promotes dissemination of multiple myeloma through acquisition of epithelial to mesenchymal transition-like features. Blood. 2012;119(24):5782-94

25. Cox J, Mann M. MaxQuant enables high peptide identification rates, individualized p.p.b.-range mass accuracies and proteome-wide protein quantification. Nature Biotechnology. 2008;26(12):1367-72.

26. Cox J, Matic I, Hilger M, Nagaraj N, Selbach M, Olsen JV, et al. A practical guide to the MaxQuant computational platform for SILAC-based quantitative proteomics. Nature Protocols. 2009;4(5):698-705.

27. Cox J, Neuhauser N, Michalski A, Scheltema RA, Olsen JV, Mann M. Andromeda: a peptide search engine integrated into the MaxQuant environment. Journal of Proteome Research. 2011;10(4):1794-805.

28. Berard AR, Cortens JP, Krokhin O, Wilkins JA, Severini A, Coombs KM. Quantification of the host response proteome after mammalian reovirus T1L infection. PloS One. 2012;7(12):17.

29. Coombs KM, Berard A, Xu W, Krokhin O, Meng X, Cortens JP, et al. Quantitative proteomic analyses of 
influenza virus-infected cultured human lung cells. Journal of Virology. 2010;84(20):10888-906.

30. Camon E, Magrane M, Barrell D, Binns D, Fleischmann W, Kersey P, et al. The Gene Ontology Annotation (GOA) project: implementation of GO in SWISS-PROT, TrEMBL, and InterPro. Genome Research. 2003;13(4):662-72.

31. Huang DW, Sherman BT, Tan Q, Kir J, Liu D, Bryant D, et al. DAVID Bioinformatics Resources: expanded annotation database and novel algorithms to better extract biology from large gene lists. Nucleic Acids Research. 2007;35(Web Server):W169-W75.

32. Huang DW, Sherman BT, Lempicki RA. Systematic and integrative analysis of large gene lists using DAVID bioinformatics resources. Nature Protocols. 2009;4(1):14.

33. Li X, Li D, Pang X, Yang G, Deeg HJ, Guan F. Quantitative analysis of glycans, related genes, and proteins in two human bone marrow stromal cell lines using an integrated strategy. Experimental Hematology. 2015;43(9):760-9.

34. Uruno T, Zhang P, Jiali L, Jian-Jiang H, Xi Z. Haematopoietic lineage cell-specific protein 1 (HS1) promotes actin-related protein (Arp) 2/3 complex-mediated actin polymerization. Biochemical Journal. $2003 ; 371(2): 485-93$.

35. Takagi M, Shinohara H, Narumi S, Nishimura G, Hasegawa Y, Hasegawa T. Severe osteogenesis imperfecta caused by double glycine substitutions near the amino-terminal triple helical region in COL1A2. American Journal of Medical Genetics Part A. 2015;167(7):1627-31.

36. Fernández MM, Ferragut F, Delgado VMC, Bracalente C, Bravo AI, Cagnoni AJ, et al. Glycosylation-dependent binding of galectin- 8 to activated leukocyte cell adhesion molecule (ALCAM/CD166) promotes its surface segregation on breast cancer cells. Biochimica et Biophysica Acta (BBA)-General Subjects. 2016.

37. Hooker R, Chitteti B, Egan P, Cheng Y, Himes E, Meijome T, et al. Activated leukocyte cell adhesion molecule (ALCAM or CD166) modulates bone phenotype and hematopoiesis. J Musculoskelet Neuronal Interact. 2015;15(1):83-94.

38. Jiang Y, Shang L, Shi Z, Zhang T, Ma S, Lu C, et al. Microtubule-associated protein 4 is an important regulator of cell invasion/migration and a potential therapeutic target in esophageal squamous cell carcinoma. Oncogene. 2016.

39. Chang W, Gruber D, Chari S, Kitazawa H, Hamazumi Y, Hisanaga S-i, et al. Phosphorylation of MAP4 affects microtubule properties and cell cycle progression. Journal of Cell Science. 2001;114(15):2879-87.

40. Chiosis G, Caldas LE, Solit D. Heat shock protein-90 inhibitors: a chronicle from geldanamycin to today's agents. Current Opinion in Investigational Drugs (London, England: 2000). 2006;7(6):534-41.

41. Liao C-F, Lin S-H, Chen H-C, Tai C-J, Chang C-C, Li L-T, et al. CSE1L, a novel microvesicle membrane protein, mediates Ras-triggered microvesicle generation and metastasis of tumor cells. Molecular Medicine. 
2012;18(1):1269.

42. Wasil L, Shair K. Epstein-Barr virus LMP1 induces focal adhesions and epithelial cell migration through effects on integrin- $\alpha 5$ and $\mathrm{N}$-cadherin. Oncogenesis. 2015;4(10):e171. 
Table 1: Protein number, $\log _{2}$ ratio, and z-scores of SILAC-labeled proteins.

\begin{tabular}{lllll}
\hline \multirow{2}{*}{ Cell line type } & Protein & \multicolumn{2}{l}{ Z-score $^{\mathrm{b}}$} & \\
\cline { 3 - 5 } & number $^{\mathrm{a}}$ & $\pm 1.960 \sigma$ & $\pm 2.576 \sigma$ & $\pm 3.291 \sigma$ \\
\hline HS27a/HS5 (H/L) & 1462 & 69,48 & 34,26 & 16,12 \\
\hline
\end{tabular}

${ }^{\mathrm{a}}$ Proteins were analyzed in two independent experiments.

${ }^{\mathrm{b}} \mathrm{Z}$-score value is the average $\log _{2}$ ratio (HS27a/HS5). Numbers of upregulated and downregulated proteins outside the indicated confidence level are shown. 
Table 2: Downregulated proteins in HS27a cells in comparison with HS5 (>95\% confidence).

\begin{tabular}{|c|c|c|c|c|}
\hline Protein ID & Protein name & Gene name & $\begin{array}{l}\log _{2} \\
\text { ratio }\end{array}$ & Z-score ${ }^{a}$ \\
\hline H0Y8D1 & $\begin{array}{l}\text { Putative trypsin-6;Trypsin-2;Trypsin-1;Alpha-trypsin chain } 1 ; \\
\text { Alpha-trypsin chain } 2\end{array}$ & PRSS1 & -4.896 & -5.461 \\
\hline P35908 & Keratin, type II cytoskeletal 2 epidermal & KRT2 & -3.680 & -4.113 \\
\hline P04264 & Keratin, type II cytoskeletal 1 & KRT1 & -3.469 & -3.879 \\
\hline P12277 & Creatine kinase B-type & $\mathrm{CKB}$ & -3.207 & -3.588 \\
\hline Q96FQ6 & Protein S100-A16 & S100A16 & -3.082 & -3.450 \\
\hline P35527 & Keratin, type I cytoskeletal 9 & KRT9 & -3.076 & -3.443 \\
\hline B9A047 & Ankyrin repeat and SOCS box protein 1 & ASB1 & -3.065 & -3.430 \\
\hline P02769 & Serum albumin & ALB & -3.061 & -3.426 \\
\hline P81644 & Apolipoprotein A-II & APOA2 & -2.976 & -3.332 \\
\hline Q9Y2J2 & Band 4.1-like protein 3 & EPB41L3 & -2.930 & -3.281 \\
\hline Q5TA02 & Glutathione S-transferase omega-1 & GSTO1 & -2.829 & -3.169 \\
\hline P13645 & Keratin, type I cytoskeletal 10 & KRT10 & -2.664 & -2.986 \\
\hline D3DR31 & Interferon-induced protein with tetratricopeptide repeats 1 & IFIT1 & -2.633 & -2.951 \\
\hline P12763 & Alpha-2-HS-glycoprotein & AHSG & -2.593 & -2.907 \\
\hline F6SKP1 & Transmembrane glycoprotein NMB & GPNMB & -2.576 & -2.888 \\
\hline Q99541 & Perilipin-2 & PLIN2 & -2.481 & -2.782 \\
\hline H7C3P7 & Ras-related protein Ral-A & RALA & -2.437 & -2.733 \\
\hline O14879 & Interferon-induced protein with tetratricopeptide repeats 3 & IFIT3 & -2.400 & -2.693 \\
\hline P55060 & Exportin-2 & CSE1L & -2.395 & -2.687 \\
\hline P03956 & $\begin{array}{l}\text { Interstitial collagenase; } 22 \mathrm{kDa} \text { interstitial collagenase; } 27 \mathrm{kDa} \\
\text { interstitial collagenase }\end{array}$ & MMP1 & -2.351 & -2.638 \\
\hline P15924 & Desmoplakin & DSP & -2.342 & -2.629 \\
\hline Q9GZL7 & Ribosome biogenesis protein WDR12 & WDR12 & -2.309 & -2.591 \\
\hline Q14141 & Septin-6 & 41888 & -2.295 & -2.577 \\
\hline P09913 & Interferon-induced protein with tetratricopeptide repeats 2 & IFIT2 & -2.102 & -2.363 \\
\hline Q5SW79 & Centrosomal protein of $170 \mathrm{kDa}$ & CEP170 & -2.097 & -2.356 \\
\hline P35610 & Sterol O-acyltransferase 1 & SOAT1 & -2.075 & -2.332 \\
\hline P05120 & Plasminogen activator inhibitor 2 & SERPINB2 & -2.050 & -2.304 \\
\hline P01130 & Low-density lipoprotein receptor & LDLR & -1.922 & -2.163 \\
\hline P05161 & Ubiquitin-like protein ISG15 & ISG15 & -1.830 & -2.060 \\
\hline P17096 & High mobility group protein HMG-I/HMG-Y & HMGA1 & -1.828 & -2.058 \\
\hline P29992 & Guanine nucleotide-binding protein subunit alpha-11 & GNA11 & -1.816 & -2.045 \\
\hline Q9BZV1 & UBX domain-containing protein 6 & UBXN6 & -1.800 & -2.028 \\
\hline P07858 & Cathepsin B; Cathepsin B light chain; Cathepsin B heavy chain & CTSB & -1.790 & -2.016 \\
\hline Q53EL6 & Programmed cell death protein 4 & PDCD4 & -1.790 & -2.016 \\
\hline P40189 & Interleukin-6 receptor subunit beta & IL6ST & -1.785 & -2.011 \\
\hline E9PDL6 & Protein NDRG1 & NDRG1 & -1.767 & -1.991 \\
\hline P18031 & $\begin{array}{l}\text { Tyrosine-protein phosphatase non-receptor type } \\
1 ; \text { Tyrosine-protein phosphatase non-receptor type }\end{array}$ & PTPN1 & -1.757 & -1.979 \\
\hline B4DGD3 & Uridine-cytidine kinase 2 & UCK2 & -1.749 & -1.971 \\
\hline Q9BZQ8 & Protein Niban & FAM129A & -1.749 & -1.971 \\
\hline Q86TI2-4 & Dipeptidyl peptidase 9 & DPP9 & -1.705 & -1.922 \\
\hline Q9NQZ5 & StAR-related lipid transfer protein 7 , mitochondrial & STARD7 & -1.689 & -1.904 \\
\hline C9JG97 & Angio-associated migratory cell protein & AAMP & -1.661 & -1.873 \\
\hline Q5T3Q7 & HEAT repeat-containing protein 1 & HEATR1 & -1.643 & -1.853 \\
\hline P51570 & Galactokinase & GALK1 & -1.627 & -1.835 \\
\hline Q16643 & Drebrin & DBN1 & -1.602 & -1.807 \\
\hline Q9NYY8 & FAST kinase domain-containing protein 2 & FASTKD2 & -1.584 & -1.788 \\
\hline K7EIG1 & Clustered mitochondria protein homolog & CLUH & -1.576 & -1.779 \\
\hline P13639 & Elongation factor 2 & EEF2 & -1.568 & -1.770 \\
\hline
\end{tabular}

${ }^{\mathrm{a}} \mathrm{Z}$-score: average $\log _{2}$ ratio $=0.027 . \mathrm{SD}=0.901 ; 95 \%$ confidence cutoff: $-1.960 \sigma=-1.766$. 
Table 3: Upregulated proteins in HS27a in comparison with HS5 (>95\% confidence).

\begin{tabular}{|c|c|c|c|c|}
\hline Protein ID & Protein name & Gene name & $\begin{array}{l}\log _{2} \\
\text { ratio }\end{array}$ & Z-score ${ }^{a}$ \\
\hline P11047 & Laminin subunit gamma-1 & LAMC1 & 1.622 & 1.769 \\
\hline Q7KZF4 & Staphylococcal nuclease domain-containing protein 1 & SND1 & 1.633 & 1.781 \\
\hline O60701 & UDP-glucose 6-dehydrogenase & UGDH & 1.643 & 1.793 \\
\hline B7Z2S5 & Thioredoxin reductase 1 , cytoplasmic & TXNRD1 & 1.666 & 1.817 \\
\hline Q9UEY8 & Adducin 3 & ADD3 & 1.678 & 1.831 \\
\hline P49257 & Protein ERGIC-53 & LMAN1 & 1.685 & 1.839 \\
\hline Q16352 & Alpha-internexin & INA & 1.697 & 1.852 \\
\hline P13667 & Protein disulfide-isomerase A4 & PDIA4 & 1.732 & 1.891 \\
\hline P42765 & 3-ketoacyl-CoA thiolase, mitochondrial & ACAA2 & 1.746 & 1.907 \\
\hline Q96AY3 & Peptidyl-prolyl cis-trans isomerase FKBP10 & FKBP10 & 1.749 & 1.910 \\
\hline Q86UV5 & Ubiquitin carboxyl-terminal hydrolase 48 & USP48 & 1.751 & 1.912 \\
\hline H7BXI1 & Extended synaptotagmin-2 & ESYT2 & 1.761 & 1.923 \\
\hline P04792 & Heat shock protein beta-1 & HSPB1 & 1.784 & 1.949 \\
\hline Q8WX93 & Palladin & PALLD & 1.788 & 1.953 \\
\hline P60903 & Protein S100-A10 & S100A10 & 1.801 & 1.968 \\
\hline Q9P0L0 & Vesicle-associated membrane protein-associated protein A & VAPA & 1.812 & 1.980 \\
\hline Q9UDY4 & DnaJ homolog subfamily B member 4 & DNAJB4 & 1.817 & 1.985 \\
\hline Q96HC4 & PDZ and LIM domain protein 5 & PDLIM5 & 1.825 & 1.994 \\
\hline B4DKB2 & Endothelin-converting enzyme 1 & ECE1 & 1.831 & 2.001 \\
\hline P06396 & Gelsolin & GSN & 1.856 & 2.028 \\
\hline P21964 & Catechol O-methyltransferase & COMT & 1.892 & 2.068 \\
\hline F5GXJ9 & CD166 antigen & ALCAM & 1.899 & 2.076 \\
\hline P00167 & Cytochrome b5 & CYB5A & 1.903 & 2.081 \\
\hline P54687 & Branched-chain-amino-acid aminotransferase, cytosolic & BCAT1 & 1.932 & 2.113 \\
\hline P41226 & Ubiquitin-like modifier-activating enzyme 7 & UBA7 & 1.941 & 2.123 \\
\hline Q99715 & Collagen alpha-1(XII) chain & COL12A1 & 1.943 & 2.125 \\
\hline P50454 & Serpin H1 & SERPINH1 & 1.994 & 2.182 \\
\hline P14550 & Alcohol dehydrogenase [NADP(+)] & AKR1A1 & 1.996 & 2.184 \\
\hline Q15555 & Microtubule-associated protein RP/EB family member 2 & MAPRE2 & 2.014 & 2.204 \\
\hline Q86SF2 & $\mathrm{N}$-acetylgalactosaminyltransferase 7 & GALNT7 & 2.033 & 2.225 \\
\hline P07951 & Tropomyosin beta chain & TPM2 & 2.039 & 2.232 \\
\hline P32455 & Interferon-induced guanylate-binding protein 1 & GBP1 & 2.068 & 2.264 \\
\hline Q9BX68 & Histidine triad nucleotide-binding protein 2 , mitochondrial & HINT2 & 2.092 & 2.290 \\
\hline P21266 & Glutathione S-transferase Mu 3 & GSTM3 & 2.098 & 2.298 \\
\hline F8VZY9 & Keratin, type I cytoskeletal 18 & KRT18 & 2.103 & 2.303 \\
\hline P29966 & Myristoylated alanine-rich C-kinase substrate & MARCKS & 2.145 & 2.349 \\
\hline Q6EMK4 & Vasorin & VASN & 2.191 & 2.400 \\
\hline B4DIT7 & Protein-glutamine gamma-glutamyltransferase 2 & TGM2 & 2.223 & 2.436 \\
\hline $\mathrm{O} 43175$ & D-3-phosphoglycerate dehydrogenase & PHGDH & 2.288 & 2.508 \\
\hline P15121 & Aldose reductase & AKR1B1 & 2.333 & 2.558 \\
\hline P30740 & Leukocyte elastase inhibitor & SERPINB1 & 2.337 & 2.563 \\
\hline P40261 & Nicotinamide $\mathrm{N}$-methyltransferase & NNMT & 2.388 & 2.619 \\
\hline P07942 & Laminin subunit beta-1 & LAMB1 & 2.391 & 2.622 \\
\hline Q8NBJ7 & Sulfatase-modifying factor 2 & SUMF2 & 2.404 & 2.636 \\
\hline Q92896 & Golgi apparatus protein 1 & GLG1 & 2.424 & 2.659 \\
\hline Q9Y6H1 & $\begin{array}{l}\text { Coiled-coil-helix-coiled-coil-helix domain-containing protein 2, Putative } \\
\text { coiled-coil-helix-coiled-coil-helix domain-containing protein CHCHD2P9, } \\
\text { mitochondrial }\end{array}$ & CHCHD2 & 2.446 & 2.683 \\
\hline Q13642 & Four and a half LIM domains protein 1 & FHL1 & 2.452 & 2.690 \\
\hline A6NCT7 & Collagen alpha-1(XVI) chain & COL16A1 & 2.463 & 2.702 \\
\hline O43852 & Calumenin & CALU & 2.582 & 2.834 \\
\hline P20908 & Collagen alpha- $1(\mathrm{~V})$ chain & COL5A1 & 2.588 & 2.841 \\
\hline Q13636 & Ras-related protein Rab-31 & RAB31 & 2.605 & 2.860 \\
\hline P02452 & Collagen alpha-1(I) chain & COL1A1 & 2.623 & 2.879 \\
\hline F8VQR7 & Cysteine and glycine-rich protein 2 & CSRP2 & 2.644 & 2.902 \\
\hline Q15113 & Procollagen C-endopeptidase enhancer 1 & PCOLCE & 2.763 & 3.035 \\
\hline P07996 & Thrombospondin-1 & THBS1 & 2.882 & 3.166 \\
\hline E7EVW7 & Hematopoietic lineage cell-specific protein & HCLS1 & 2.979 & 3.275 \\
\hline
\end{tabular}




\begin{tabular}{lllll} 
Q9UGI8 & Testin & TES & 3.012 & 3.311 \\
P13796 & Plastin-2 & LCP1 & 3.091 & 3.399 \\
Q9Y680 & Peptidyl-prolyl cis-trans isomerase FKBP7;Peptidyl-prolyl cis-trans isomerase & FKBP7 & 3.093 & 3.400 \\
Q96D15 & Reticulocalbin-3 & RCN3 & 3.205 & 3.525 \\
P05997 & Collagen alpha-2(V) chain & COL5A2 & 3.328 & 3.662 \\
P12111 & Collagen alpha-3(VI) chain & COL6A3 & 3.387 & 3.727 \\
Q01995 & Transgelin & TAGLN & 3.552 & 3.910 \\
Q16270 & Insulin-like growth factor-binding protein 7 & IGFBP7 & 3.591 & 3.954 \\
P15151 & Poliovirus receptor & PVR & 3.602 & 3.965 \\
P02461 & Collagen alpha-1(III) chain & COL3A1 & 3.620 & 3.986 \\
P08123 & Collagen alpha-2(I) chain & COL1A2 & 3.741 & 4.120 \\
Q9UPQ0 & LIM and calponin homology domains-containing protein 1 & LIMCH1 & 3.778 & 4.161 \\
O75459 & P antigen family member 1 & PAGE1 & 4.507 & 4.969 \\
\hline
\end{tabular}

${ }^{\mathrm{a}} \mathrm{Z}$-score: average $\log _{2}$ ratio $=0.027 . \mathrm{SD}=0.901 ; 95 \%$ confidence cutoff: $1.960 \sigma=1.766$ 
Table 4: Comparison of SILAC and Gene array $\log _{2}$ ratios.

\begin{tabular}{|c|c|c|c|c|c|c|c|}
\hline No. & Protein ID & Protein name & $\begin{array}{l}\text { Gene } \\
\text { name }\end{array}$ & $\begin{array}{l}\text { Mol. } \\
\text { weight } \\
{[\mathrm{kDa}]}\end{array}$ & PEP & $\begin{array}{l}\text { SILAC } \\
\log _{2} \\
\text { ratio }\end{array}$ & $\begin{array}{l}\text { Gene } \\
\text { array } \\
\log _{2} \\
\text { ratio }\end{array}$ \\
\hline 1 & P08123 & Collagen alpha-2(I) chain & COL1A2 & 129.3 & $1.293 \mathrm{E}+02$ & 3.741 & 1.217 \\
\hline 2 & P02461 & Collagen alpha-1(III) chain & COL3A1 & 138.6 & $1.386 \mathrm{E}+02$ & 3.620 & 1.589 \\
\hline 3 & Q16270 & $\begin{array}{l}\text { Insulin-like growth factor-binding } \\
\text { protein } 7\end{array}$ & IGFBP7 & 28.9 & $2.886 \mathrm{E}+01$ & 3.591 & 4.536 \\
\hline 4 & P05997 & Collagen alpha-2(V) chain & COL5A2 & 144.9 & $1.449 \mathrm{E}+02$ & 3.328 & 2.494 \\
\hline 5 & E7EVW7 & $\begin{array}{l}\text { Hematopoietic lineage cell-specific } \\
\text { protein }\end{array}$ & HCLS1 & 49.7 & $4.970 \mathrm{E}+01$ & 2.979 & 1.685 \\
\hline 6 & F8VQR7 & Cysteine and glycine-rich protein 2 & CSRP2 & 20.7 & $2.068 \mathrm{E}+01$ & 2.644 & 1.653 \\
\hline 7 & P20908 & Collagen alpha-1(V) chain & COL5A1 & 183.6 & $1.836 \mathrm{E}+02$ & 2.588 & 1.500 \\
\hline 8 & O43852 & Calumenin & CALU & 37.1 & $3.711 \mathrm{E}+01$ & 2.582 & 1.821 \\
\hline 9 & Q13642 & $\begin{array}{l}\text { Four and a half LIM domains protein } \\
1\end{array}$ & FHL1 & 31.9 & $3.190 \mathrm{E}+01$ & 2.452 & 1.163 \\
\hline 10 & Q92896 & Golgi apparatus protein 1 & GLG1 & 134.6 & $1.346 \mathrm{E}+02$ & 2.424 & 1.043 \\
\hline 11 & P07942 & Laminin subunit beta- 1 & LAMB1 & 198.0 & $1.980 \mathrm{E}+02$ & 2.391 & 1.578 \\
\hline 12 & P40261 & Nicotinamide $\mathrm{N}$-methyltransferase & NNMT & 29.6 & $2.957 \mathrm{E}+01$ & 2.388 & 2.431 \\
\hline 13 & F8VZY9 & Keratin, type I cytoskeletal 18 & KRT18 & 43.8 & $4.377 \mathrm{E}+01$ & 2.103 & 2.887 \\
\hline 14 & P07951 & Tropomyosin beta chain & TPM2 & 33.0 & $3.299 \mathrm{E}+01$ & 2.039 & 1.634 \\
\hline 15 & Q15555 & $\begin{array}{l}\text { Microtubule-associated protein } \\
\text { RP/EB family member } 2\end{array}$ & MAPRE2 & 30.7 & $3.069 \mathrm{E}+01$ & 2.014 & 1.075 \\
\hline 16 & F5GXJ9 & CD166 antigen & ALCAM & 59.5 & $5.953 \mathrm{E}+01$ & 1.899 & 2.651 \\
\hline 17 & Q9UDY4 & $\begin{array}{l}\text { DnaJ homolog subfamily B member } \\
4\end{array}$ & DNAJB4 & 37.8 & $3.781 \mathrm{E}+01$ & 1.817 & 1.917 \\
\hline 18 & P60903 & Protein S100-A10 & S100A10 & 11.2 & $1.120 \mathrm{E}+01$ & 1.801 & 1.011 \\
\hline 19 & P42765 & $\begin{array}{l}\text { 3-ketoacyl-CoA thiolase, } \\
\text { mitochondrial }\end{array}$ & ACAA2 & 41.9 & $4.192 \mathrm{E}+01$ & 1.746 & 1.091 \\
\hline 21 & O60701 & UDP-glucose 6-dehydrogenase & UGDH & 55.0 & $5.502 \mathrm{E}+01$ & 1.643 & 1.338 \\
\hline 22 & P20962 & Parathymosin & PTMS & 11.5 & $1.153 \mathrm{E}+01$ & 1.579 & 1.097 \\
\hline 23 & P47755 & $\begin{array}{l}\text { F-actin-capping protein subunit } \\
\text { alpha-2 }\end{array}$ & CAPZA2 & 32.9 & $3.295 \mathrm{E}+01$ & 1.567 & 1.096 \\
\hline 24 & B4DEY6 & $\begin{array}{l}\text { LIM and cysteine-rich domains } \\
\text { protein } 1\end{array}$ & LMCD1 & 28.5 & $2.851 \mathrm{E}+01$ & 1.529 & 1.997 \\
\hline 25 & O60568 & $\begin{array}{l}\text { Procollagen-lysine,2-oxoglutarate } \\
\text { 5-dioxygenase } 3\end{array}$ & PLOD3 & 84.8 & $8.478 \mathrm{E}+01$ & 1.512 & 1.027 \\
\hline 26 & P61981 & $\begin{array}{l}\text { 14-3-3 protein gamma;14-3-3 } \\
\text { protein gamma, N-terminally } \\
\text { processed }\end{array}$ & YWHAG & 28.3 & $2.830 \mathrm{E}+01$ & 1.343 & 1.450 \\
\hline 27 & O15344 & Midline-1 & MID1 & 75.3 & $7.525 \mathrm{E}+01$ & 1.333 & 1.989 \\
\hline 28 & Q99805 & $\begin{array}{l}\text { Transmembrane } 9 \text { superfamily } \\
\text { member } 2\end{array}$ & TM9SF2 & 75.8 & $7.578 \mathrm{E}+01$ & 1.225 & 1.435 \\
\hline 29 & A8MWK3 & Cadherin-2 & $\mathrm{CDH} 2$ & 97.0 & $9.704 \mathrm{E}+01$ & 1.216 & 2.574 \\
\hline 30 & P30043 & Flavin reductase (NADPH) & BLVRB & 22.1 & $2.212 \mathrm{E}+01$ & 1.199 & 1.222 \\
\hline 31 & E7ETU9 & $\begin{array}{l}\text { Procollagen-lysine,2-oxoglutarate } \\
\text { 5-dioxygenase } 2\end{array}$ & PLOD2 & 81.2 & $8.117 \mathrm{E}+01$ & 1.157 & 1.598 \\
\hline 32 & Q03135 & Caveolin-1;Caveolin & CAV1 & 20.5 & $2.047 \mathrm{E}+01$ & 1.099 & 1.937 \\
\hline 33 & P30520 & $\begin{array}{l}\text { Adenylosuccinate synthetase } \\
\text { isozyme } 2\end{array}$ & ADSS & 50.1 & $5.010 \mathrm{E}+01$ & -0.995 & -1.542 \\
\hline 34 & P12109 & Collagen alpha-1(VI) chain & COL6A1 & 108.5 & $1.085 \mathrm{E}+02$ & -1.006 & -1.694 \\
\hline 35 & B8ZZQ6 & $\begin{array}{l}\text { Prothymosin alpha; Thymosin } \\
\text { alpha-1 }\end{array}$ & PTMA & 11.8 & $1.176 \mathrm{E}+01$ & -1.077 & -1.094 \\
\hline 36 & P21399 & Cytoplasmic aconitate hydratase & ACO1 & 98.4 & $9.840 \mathrm{E}+01$ & -1.256 & -2.563 \\
\hline 37 & P19367 & $\begin{array}{l}\text { Hexokinase-1;Putative hexokinase } \\
\text { HKDC1 }\end{array}$ & HK1 & 101.1 & $1.011 \mathrm{E}+02$ & -1.313 & -1.232 \\
\hline 38 & P19338 & Nucleolin & NCL & 76.6 & $7.661 \mathrm{E}+01$ & -1.324 & -1.321 \\
\hline 39 & Q9H2P0 & $\begin{array}{l}\text { Activity-dependent neuroprotector } \\
\text { homeobox protein }\end{array}$ & ADNP & 123.6 & $1.236 \mathrm{E}+02$ & -1.375 & -1.431 \\
\hline 40 & P08473 & Neprilysin & MME & 85.5 & $8.551 \mathrm{E}+01$ & -1.381 & -2.609 \\
\hline 41 & P17301 & Integrin alpha-2 & ITGA2 & 129.3 & $1.293 \mathrm{E}+02$ & -1.537 & -3.835 \\
\hline 42 & C9JG97 & $\begin{array}{l}\text { Angio-associated migratory cell } \\
\text { protein }\end{array}$ & AAMP & 44.7 & $4.469 \mathrm{E}+01$ & -1.661 & -1.146 \\
\hline 43 & P18031 & $\begin{array}{l}\text { Tyrosine-protein phosphatase } \\
\text { non-receptor type } \\
1 ; \text { Tyrosine-protein phosphatase } \\
\text { non-receptor type }\end{array}$ & PTPN1 & 50.0 & $4.997 \mathrm{E}+01$ & -1.757 & -1.373 \\
\hline 44 & P40189 & Interleukin- 6 receptor subunit beta & IL6ST & 103.5 & $1.035 \mathrm{E}+02$ & -1.785 & -1.300 \\
\hline 45 & Q53EL6 & Programmed cell death protein 4 & PDCD4 & 50.6 & $5.058 \mathrm{E}+01$ & -1.790 & -1.476 \\
\hline 46 & P05161 & Ubiquitin-like protein ISG15 & ISG15 & 17.9 & $1.789 \mathrm{E}+01$ & -1.830 & -2.258 \\
\hline 47 & P05120 & Plasminogen activator inhibitor 2 & $\begin{array}{l}\text { SERPIN } \\
\text { B2 }\end{array}$ & 46.6 & $4.660 \mathrm{E}+01$ & -2.050 & -5.542 \\
\hline 48 & P35610 & Sterol O-acyltransferase 1 & SOAT1 & 64.7 & $6.473 \mathrm{E}+01$ & -2.075 & -1.096 \\
\hline
\end{tabular}




\begin{tabular}{llllllll}
49 & P15924 & Desmoplakin & DSP & 260.1 & $2.601 \mathrm{E}+02$ & -2.342 & -2.289 \\
50 & P55060 & Exportin-2 & CSE1L & 107.8 & $1.078 \mathrm{E}+02$ & -2.395 & -1.572 \\
51 & F6SKP1 & Transmembrane glycoprotein NMB & GPNMB & 51.1 & $5.113 \mathrm{E}+01$ & -2.576 & -5.310 \\
52 & D3DR31 & Interferon-induced protein with & IFIT1 & 51.7 & $5.171 \mathrm{E}+01$ & -2.633 & -2.335 \\
53 & Q9Y2J2 & Band 4.1-like protein 3 & EPB41L3 & 96.5 & $9.651 \mathrm{E}+01$ & -2.930 & -6.749 \\
54 & B9A047 & Ankyrin repeat and SOCS box & ASB1 & 26.2 & $2.617 \mathrm{E}+01$ & -3.065 & -2.236 \\
55 & P12277 & Crotein 1 & CKB & 42.6 & $4.264 \mathrm{E}+01$ & -3.207 & -1.468 \\
\hline
\end{tabular}

$\log _{2}$ ratios are HS27a/HS5. MS data are consistent with gene array data. 


\section{Figure Legends}

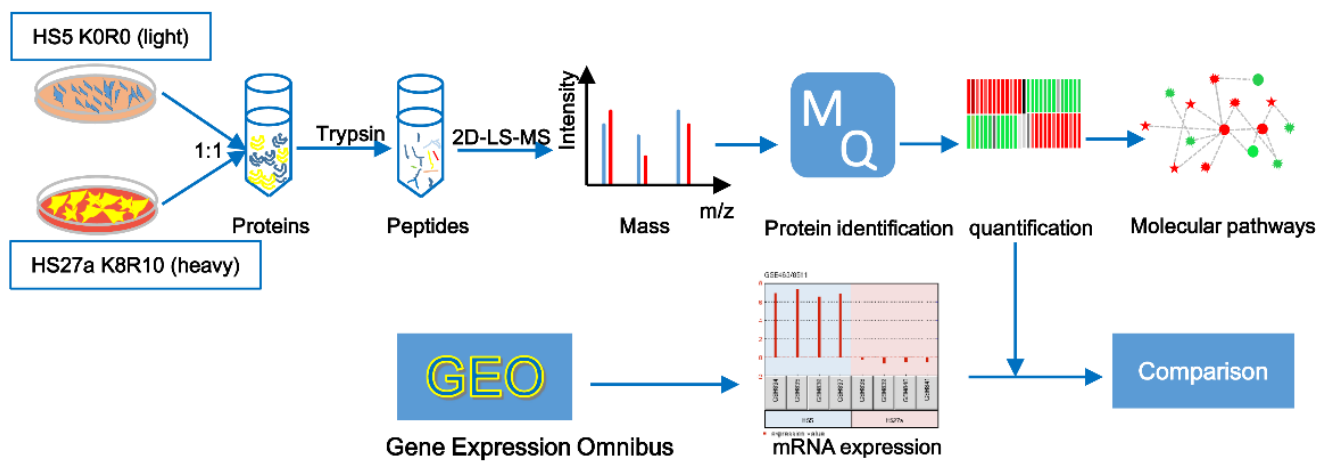

Figure 1: Schematic procedure for quantitative analysis of proteins and genes in HS5/ HS27a comparison. 
A
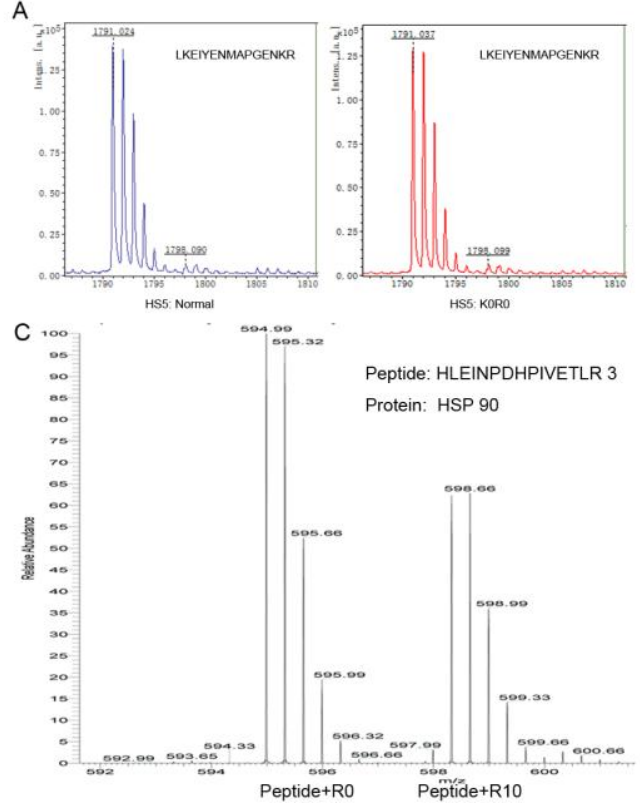

B
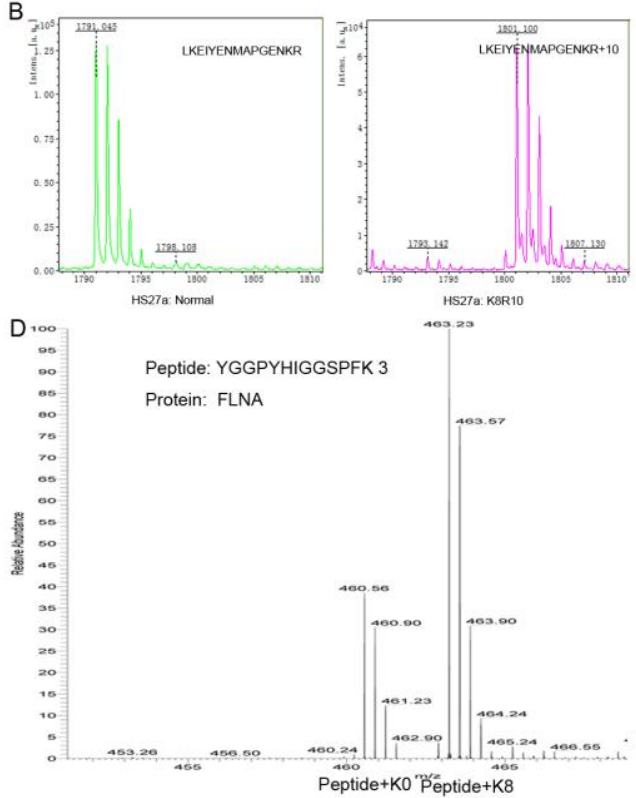

Figure 2: MS analysis of stable isotope-labeled proteins (SILAC method).

(A), (B): Determination of incorporation efficiency by MALDI-TOF/TOF-MS. Peaks annotated as normal vs. R0 (left) and normal vs. R10 (right) are peptide GVVDSEDLPLNISR of HSP90 $\beta$ from HS5 and HS27a cells, respectively.

(C), (D): Identification and quantification of proteome in HS5 and HS27a by 2D-HPLC LTQ Orbitrap MS. Peaks annotated as R0 and R10 (left) and K0 and K8 (right) are triply-charged peptide HLEINPDHPIVETLR of HSP90ß (P08238) and YGGPYHIGGSPFK of filamin-A (P21333), respectively. 

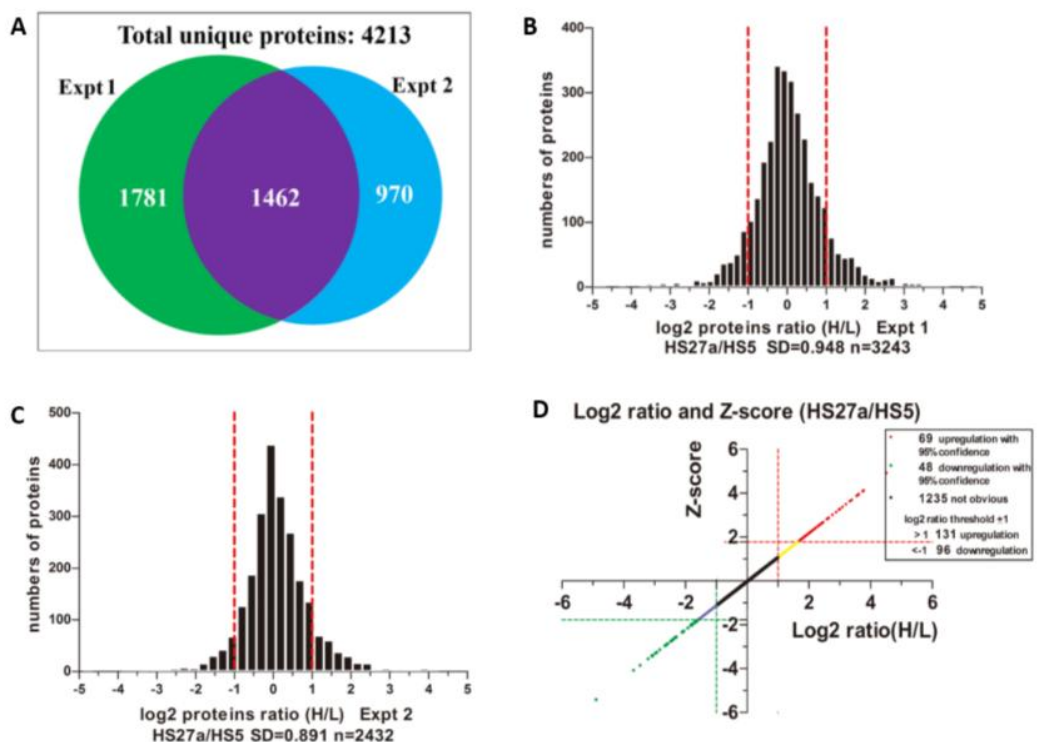

Figure 3: Distributions of proteins identified in various experiments described in the text.

(A): Venn diagrams of numbers of identified proteins from two experiments.

(B), (C): Distribution of SILAC $\mathrm{H} / \mathrm{L}$ ratios from two experiments.

(D): Ratios of HS27a/HS5 (H/L) for the set of 1462 proteins. $\log _{2}$ of the SILAC ratio and z-score for each protein $(n=2)$ reflect differences in relative expression between HS27a and HS5. 

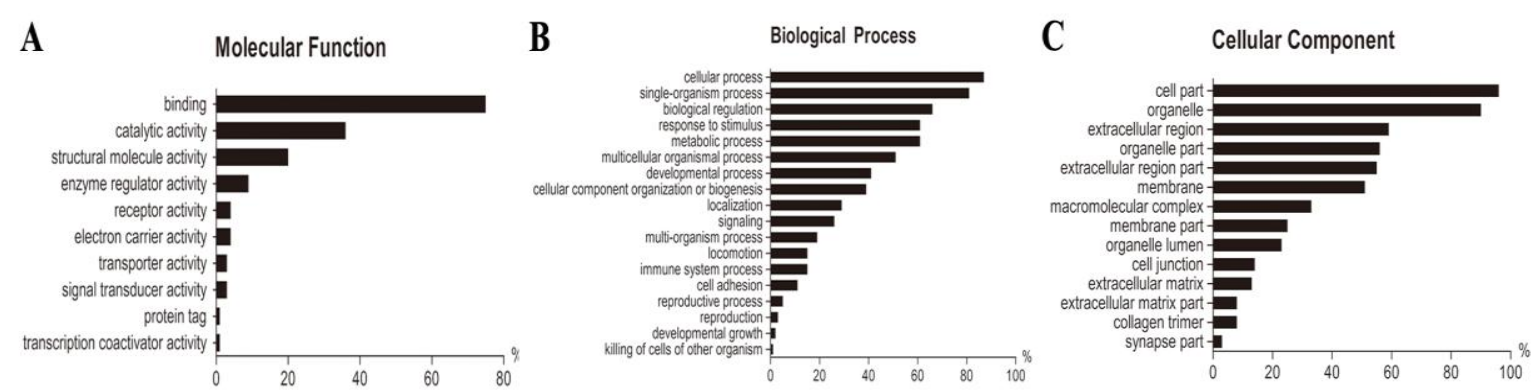

Figure 4: Functional classification of identified proteins using the SWISS-PROT database, based on universal GO annotation terms. Proteins shown were linked to at least one annotation term within the GO molecular function (A), biological process (B), and cellular component (C) categories. 


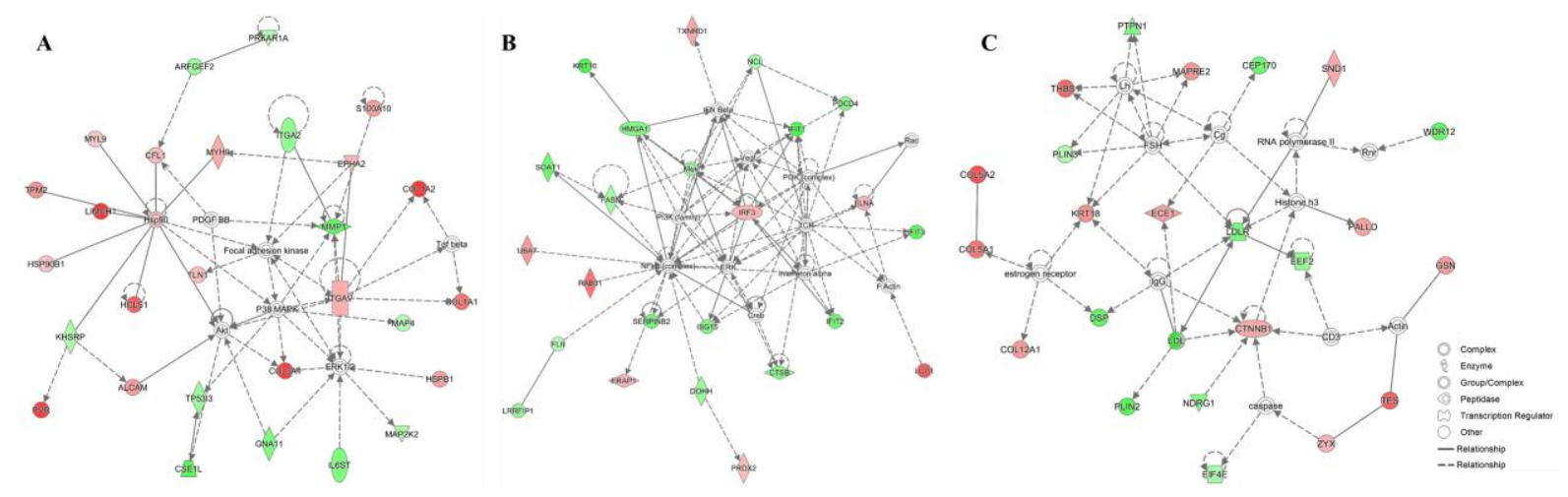

Figure 5: Functional network analysis of differentially regulated proteins with z-score cutoff $95 \%$ observed in HS5 and HS27a using Ingenuity Pathway Analysis (IPA). Top network functions include cellular movement, cell-to-cell signaling and interaction, hematological system development and function (A); infectious diseases, post-translational modification, protein folding (B); connective tissue disorders, dermatological diseases and conditions, developmental disorders (C). Red icons: upregulation of protein in HS27a relative to HS5. Green icons: downregulation of protein in HS27a relative to HS5. Color intensity indicates degree of variation. 
A

\begin{tabular}{|c|c|c|c|}
\hline Gene symbol & Gene annotation & $\begin{array}{c}\text { Gene array } \\
\log _{2}(\text { HS27a/HS5) }\end{array}$ & $\begin{array}{c}\text { SILAC ratio } \\
\log _{2}(\mathrm{HS} 27 \mathrm{a} / \mathrm{HS} 5)\end{array}$ \\
\hline HCLS1 & $\begin{array}{c}\text { Hematopoietic } \\
\text { lineage cell-specific } \\
\text { protein }\end{array}$ & 1.685 & 2.979 \\
\hline COL1A2 & $\begin{array}{c}\text { Collagen alpha-2(I) } \\
\text { chain }\end{array}$ & 0.309 & 3.741 \\
\hline ALCAM & CD166 antigen & 2.651 & 1.899 \\
\hline ITGAV & Integrin alpha-V & -0.459 & 1.510 \\
\hline MAP4 & $\begin{array}{l}\text { Microtubule- } \\
\text { associated protein }\end{array}$ & -0.098 & -1.076 \\
\hline HSP90 & $\begin{array}{l}\text { Heat shock protein } \\
\text { 90-beta }\end{array}$ & -0.005 & -0.364 \\
\hline CSE1L & Exportin-2 & -1.572 & -2.395 \\
\hline
\end{tabular}

B

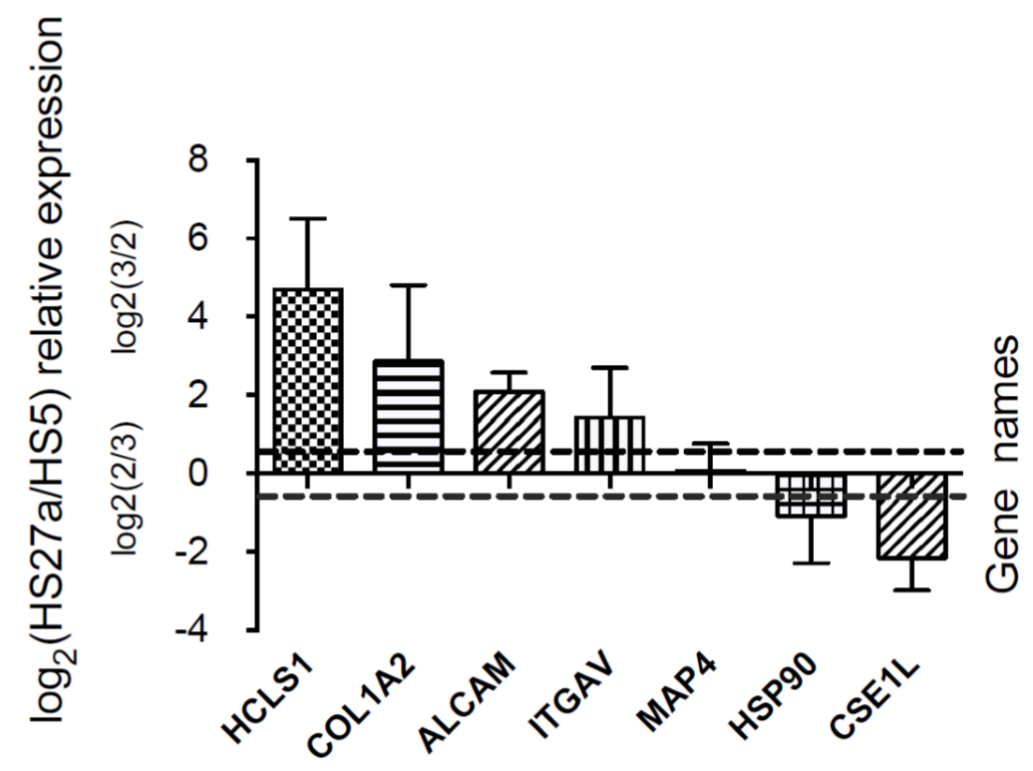


C

HS5 HS27a

HCLS1

COL1A2

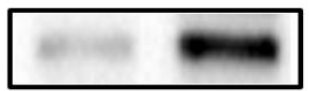

ALCAM

ITGAV

MAP4

HSP90

CSE1L

Tubulin
D

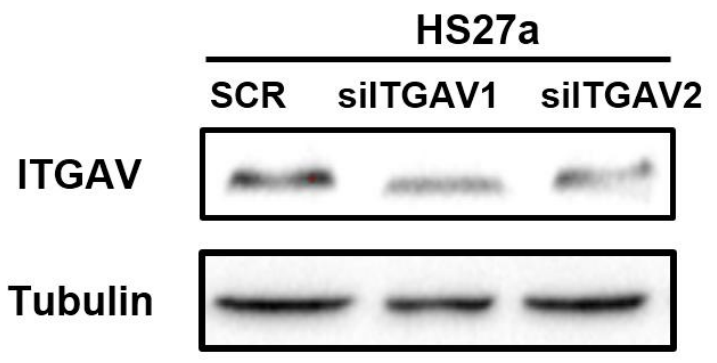

$E$

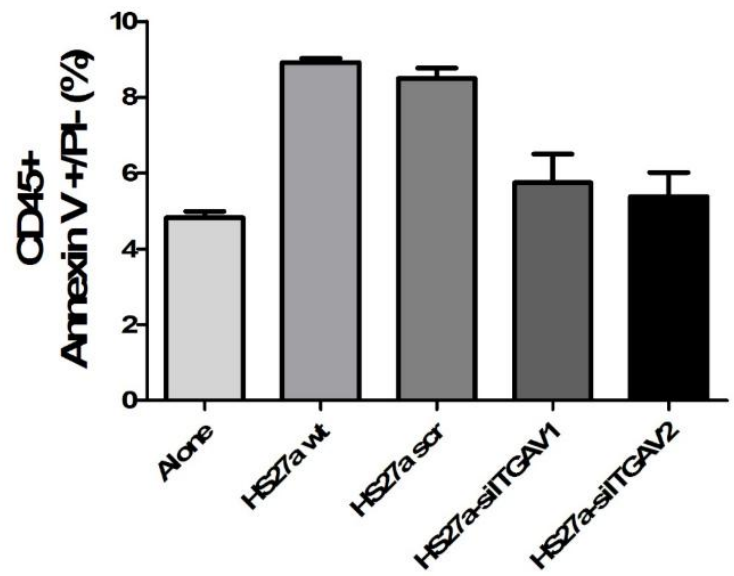

Figure 6: Validation of MS results by RT-PCR.

(A) Randomly selected genes in the two cell lines (see text).

(B) Gene expression for randomly selected proteins was analyzed by quantitative RT-PCR. Relative expression in comparison with control samples was analyzed by the $2^{-\Delta \Delta \mathrm{Ct}}$ method and represented as $\log _{2}$. Expression of genes above $\log _{2}(2)$ or below $\log _{2}(1 / 2)$ was significantly upregulated or down-regulated, respectively.

(C) Protein expression of HCLS1, COL1A2, ALCAM, ITGAV, MAP4, HSP90, and CSE1L was analyzed by western blotting.

(D)Expression of ITGAV in HS27a cells transfected with scrambled siRNA (SCR) or ITGAV-specific siRNA (siITGAV1 and siITGAV2). ITGAV expression was determined by Western blot. Tubulin served as control.

(E) Early-stage apoptosis induced by TNF $\alpha(25 \mathrm{ng} / \mathrm{mL})$ in KG1a cells in contact with or without HS27a or HS27a modified by transfection with a scrambled siRNA sequence (scr) or siRNA specific for ITGAV (siITGAV1 and siITGAV2). Apoptosis was determined by flow cytometry. Only CD45 (KG1a) cells were considered. Error bars indicate SEM. 